\title{
One Approach to Establishing a Research Center in Today's University Environment
}

Dennis Molfese, Mildred Francis Thompson Professor; Director, Center for Brain, Biology, and Behavior, University of Nebraska-Lincoln

$\mathrm{B}$ ackground: In the fall of 2010, the University of Nebraska-Lincoln recruited a senior investigator to build an interdisciplinary brain-imaging center. This recruitment developed from an initial faculty initiative, Systems Biology of Social Behavior (SB2). This initiative was supported by several departments within the College of Arts and Sciences. These included Anthropology, Biological Sciences Political Science, Psychology and Sociology. Core members of that initiative had established a significant track record of funding through NSF and NIH. This interdepartmental initiative quickly gained ground with other departments within the College and caught the attention and support of the University's research administration. The faculty made effective use of the University's internal grants program to secure additional funding support for further organizational work and planning.

In the meantime, the Dean of the College met with the involved faculty and worked with them to identify resources in terms of future faculty lines, space and other support. In addition, a grant proposal was drafted and submitted to NSF's Integrative Graduate Education and Research Traineeship Program (IGERT) involving these departments. Although that proposal received high marks, it was not funded. However, NSF invited one of the lead authors to serve on a review panel for the next grant review cycle for other IGERT applications. The review panel experience provided him with the opportunity to learn more about the grant review process that then helped in revising their earlier application. In addition, the University's Research Office made arrangements for a small panel of external experts to review the revised application before resubmission and provide detailed feedback to the organizers. That feedback proved invaluable and the document was significantly edited in light of those comments and comments provided through the previous review. Subsequently, a revision of the original application was submitted for the next round of applications.

As part of these grant initiatives, faculty from traditional behaviorallyoriented departments requested access to state-of-the-art brain imaging equipment to address non-traditional questions related to their own fields of study. In response to this groundswell of support, the Administration and faculty worked in unison to recruit senior faculty including someone familiar with advanced brain imaging techniques to help build on and develop further this initiative. Today, one year later, an officially 
designated "Center for Brain, Biology and Behavior," exists that houses two different functioning brain imaging systems (high-density EEG, NIR) with a third type (fMRI) on order. The first two systems are now being used to train interested faculty and students while others who have completed their training are using these systems to conduct experiments. In addition, ground was broken last spring to erect a building with 24,500 square feet set aside to house the Center, the brain imaging equipment, a series of dedicated and communal laboratories and its interdisciplinary faculty. The building was part of a football stadium expansion project that added additional reserved boxes for revenues. Following initial discussions on the incidence and management of concussions in athletes, the Athletics Department proposed that a portion of that building be set aside for the research Center.

Administrative Support. The Administration, of course, controls and oversees the distribution of University resources. In this era of continuing cutbacks in funding for higher education at the state and local levels and the sharp reduction in monies available to federal grants and contracts, the management of increasingly scarce resources has become even more critical. Decisions must be made in part on the basis of which priorities are more likely to best advance the aims (if not the survival) of the institution. In the case of the University of $\mathrm{Ne}$ braska-Lincoln, the Administration recognized the benefits of the faculty initiative and decided to focus on it as one of its major priorities for the year. This involved the commitment of the A\&S College Dean, upper administration and individual departments to identify additional faculty lines, monies to cover salaries, recruitment packages, and the space to house such an endeavor. At the same time, working together they developed a set of goals that they used in part in discussions with faculty as well as part of their evaluations of potential candidates to lead the Center initiative.

Faculty Support. Faculty support is essential to the success of any large-scale initiative within the University. Faculty and their students must support the initiative not only verbally but must be willing to commit their own time and energy to pursuing the goals of the initiative. They also must both recognize that their time commitment will be significant and be willing to invest their own energies in pursuit of activities that utilize and advance Center objectives. This is not a trivial commitment. These faculty and students are already pursuing their own research and training interests that first brought them to the University. Now they must commit hours of their time to learning to use new technologies and methods as well as a research literature that uses a different vocabulary and concepts from what they previously experienced. At the same time, of course, Center objectives must also be congruent with faculty interests and goals. In our case, the faculty and Administration had already begun to develop a shared vision as part of the $\mathrm{SB}^{2}$ initiative. The vision was in no way complete but was continuing to develop. At some point it became clear that they needed someone who could dedicate more time to organize and advance the vision. At that point they began an external search for a Center Director. 
The Evolution of the Center and the Center Director Position. Initially, the University was not seeking to establish a Center nor looking for a Center Director. Instead, the Chancellor had called on the faculty to identify senior, productive researchers who might be recruited to strengthen the University's research productivity and grant success. Because of the interdisciplinary interest in the $\mathrm{SB}^{2}$ initiative, one nominated scientist came under more intense scrutiny and was invited to interview as a potential addition to this interdisciplinary effort. However, as discussions progressed between the candidate and the A\&S Dean as well as the Vice Chancellor for Research and Economic Development, a vision of other possibilities began to emerge. The Dean of A\&S and the Vice Chancellor for Research asked for a business plan to organize and articulate the candidate's vision for further developing the $\mathrm{SB}^{2}$ initiative. Given that both the $\mathrm{SB}^{2}$ faculty and the candidate were interested in utilizing a range of neuroimaging tools to study the relationship between brain and behavior, the candidate developed a 10-page business plan that reviewed the $\mathrm{SB}^{2}$ initiative and made recommendations about the kinds of facilities and equipment that would be needed to advance that initiative. This plan included cost-benefit estimates on whether to pay fees to access current brain imaging systems in the region or to obtain new and dedicated systems that would provide more ready access to faculty and students. Costs and benefits were estimated in terms of immediate access, travel time, and costs per use vs. the use of grant submissions to obtain such equipment vs. the outright pur- chase of equipment. Estimates were also provided concerning the types of essential staff needed for such an undertaking as well as their costs. A voucher plan was also proposed that would enable non-funded investigators to obtain small grants to pay for fMRI time while they developed their expertise and the publications and pilot data necessary to support their NIH grant applications. During this process the Vice Chancellor and other administrators began to consider committing significant resources to fund such a business plan.

In addition, both administrators and faculty asked questions concerning how one would engage faculty with no prior experience in brain research to engage in such an enterprise, what equipment would be important to procure, how such equipment could be obtained, how faculty, graduate and undergraduate students could be trained to use the equipment in a timely and cost-effective fashion, how to secure external and internal funding to support such a Center, what agencies to approach for funding, how best to present such funding requests, who should be associated with such a Center, its administrative structure, space needs, what staff hires would be essential to initiating its operation, the feasibility of and strategies for making such a Center self-supporting, as well as an estimate of when it actually could meet that goal. Within approximately six weeks of the initial interview, plans were emerging for an interdisciplinary Center founded on the SB2 initiative, a Center Director was hired, space was identified to house the Center, and significant funds were committed to purchase an fMRI as well as EEG imag- 
ing equipment, supplies and hire support staff.

Elements Critical to the Success of a Center. For a Center to be successfully established and thrive, there are a list of critical elements to be considered, addressed and obtained: (1) sufficient faculty interest, (2) the means to grow additional interest and involvement in the Center from other faculty and students, (3) Administrative interest and support that overlaps faculty interests, (4) the acquisition and maintenance of core facilities including equipment that promote the goals of the Center, (5) the success of common activities to facilitate professional interactions, (6) an effective training program for Center participants in the use of Center equipment and facilities, (7) an automated computer based scheduling program to maximize the effective use of those core facilities, (8) a means to foster not only individual but group collaborative grant development projects to federal and private agencies, and (9) a strong external panel of expert advisors willing to lend their expertise to support the Center's success.

Strategies for Estimating the Startup Costs for Such a Center. The preceding paragraph lists nine key elements that are viewed as critical to developing a successful Center. Negotiations with administration regarding potential startup costs should address some if not all of those points. While not all routinely have a monetary cost, all are important. Without points 1 through 3 , the likelihood of success is limited and attempts to start such a Center would be premature. It is easy to focus on point 4 concerning core facilities or equipment. This equipment must be state of the art, user accessible, and have a history of cost-effective and scientifically sound service. In considering equipment, annual maintenance charges must also be factored in as a cost. Consulting with experts in the field can lead to the identification of individual pieces of equipment including models and costs. Inquiries regarding software acquisition and analysis packages widely used in the fields of study, their availability to your Center at cost or at no cost, are critical prior to developing a final list to be submitted to the administration. Training in the use of the equipment, standard test procedures as well as safety procedures are always important and critical factors. If the equipment is not used correctly or abused, the research programs will suffer and time will be lost in costly repairs or wasted test sessions. To maximize usage, training should be available for faculty, postdoctoral fellows, visiting scientists, graduate students as well as undergraduate students. Depending on the complexity of the equipment and procedures, the trainer could also have one or two additional although less time consuming responsibilities. Many Centers found the use of automated scheduling programs to be quite cost effective, maximizing the use of equipment as well as research space. If an investigator cancels a test within a few hours of the scheduled time and alerts the system, an automated call goes out to an ordered list of investigators indicating that equipment and/or space is available within a certain timeframe if they contact the system. If there is not reply, the next individual or group requesting time is then alerted and the sequence repeated. Encouraging collabora- 
tive as well as individual grant initiatives is important to the Center's success. A universal dictum is that Centers should at some point become selfsupporting through grants and contracts. If a research office is not available to Center personnel through the parent institution, then recruiting research consultants who are expert in institutional grants and contracts will be an additional cost. Even so, numerous Centers over time have developed their own grant submission support staff as a means of providing more direct contact with the grant writers during that process.

Reporting Lines for a Center. Every University has a different approach to this issue. Some institutions such as the University of Missouri, Columbia, maintain an imaging center within a specific department. In their case, this is the Department of Psychology. Other institutions have established stand-alone Centers that are overseen directly by an upper administrative level or are maintained as part of a medical school as is the case at Yale University. Different approaches work well in different environments. Some argue that if the focus of the Center is on a faculty within a College, it is reasonable to keep the reporting lines for the Director of the Center restricted to that Dean, with input from departments that make up the college. On the other hand, if the Center is to have a broader level of involvement across the University, then the Center should be able to draw on guidance from the next level of administration. Given the involvement of different colleges at this level, it might make sense for the College Deans to also play some role in advising the Center. In our par- ticular case, given the broad involvement of so many departments across all the colleges, an administrative decision was made to have the Center Director report directly to the Vice Chancellor for Research and Economic Development. Other University-wide Centers also report to this office as well as the University's research support office.

The Continuing Role of Faculty and Students. At the same time, of course, faculty and students directly involved in Center activities should play a role in Center policy and direction. Routine issues for the Center to address range from space management to recruitment and the use of resources. Faculty groups such as SB2 play important roles, both in helping to define the missions of the Center as well as serving as a successful model for other initiatives whose success depends upon the integration of faculty interests in pursuit of break-through research and training initiatives. An external advisory panel composed of other Center directors as well as prominent scientists should be identified and retained. Yearly meetings of this group provide important guidance to the Center in its mission. These meetings also form the basis for a yearly conference to promote Center accomplishments through the publication of edited books and special journal issues.

Training: For such a Center to develop and thrive, of course, it must not only attract administrative, faculty and student interest but must also train users in a maximally efficient way so as not to disrupt their other professional commitments. Moreover, such training must lead to efficient and effective use of Center resources including the imaging 
equipment so that the new users can publish and become competitive in securing external grant support to advance their studies and careers. These are all issues that we are currently addressing. In the brief period between October 1, 2010 and July, 2011, the Center has grown beyond its roots within the College of Arts and Sciences to encompass literally every college within the University. As a result, it has become thoroughly interdisciplinary, including faculty and students from music and art to anthropology, political science, psychology and education. Some 134 faculties along with their graduate and undergraduate students have completed our two-day workshops on methods, theory and applications. An additional 32 individuals are involved in different levels of training in using the advanced imaging equipment to collect data. At this point three different research groups have begun their testing of subjects in their own designed studies with their own testing personnel. All of these trainees are a part of our seven step training program is now in place to train faculty and students in the use of the advanced imaging equipment and procedures.

Seven Training Steps. The training program we adopted was designed to introduce the initiate to the major theoretical, methodological and technical aspects of the field of neuroimaging and cognitive neuroscience in as short a time as possible but also with as much hands on experience as possible. Training involved an initial overview of cognitive neuroscience and brain imaging techniques that are directly related to the interests of the audience who, for the most part, only has conducted investigations into behavior. The ultimate goal of these seven steps is to take the attendees from novice to an informed investigator who can design, conduct, and analyze studies involving the technique and who will then be able to submit conference papers, articles to their professional journals and, eventually, grant submissions to obtain funding to continue support for their work.

To pursue and support such a model, we developed the following sevenstep training plan:

1. Interested participants first volunteered to attend a two-day (20 hour) workshop on the history, research questions, methods and technology involved in any of the types of brain imaging methods that we currently have available - fMRI, high-density ERP/EEG, and Near-Infrared Spectroscopy (NIRS).

2. Twenty-five hours of training in the set-up, design and operation of the equipment to obtain the brain imaging data as well as the development of materials needed for submission to the University's IRB committee. A "boot camp" written and performance exam is administered by the lab director to each trainee to verify that each trainee is expert in their data collection procedures.

3. Approximately 10 hours of training in the development, construction and testing of stimulus presentation programs.

4. The actual recruitment and testing of participants. Our staff monitors the first five live tests to verify that the trainee is proficient in all aspects of the procedures from recruitment to pre-test setup, to data collection and data backup. 
5. Next, trainees receive approximately 15 to 20 hours instruction in basic data analysis procedures, using the data they collected.

6. Once data analyses are completed, trainees are assisted in developing conference submission abstracts. Once the abstract is submitted, we work with the trainee to expand the conference abstract into a journal article for submission.

7. Once two manuscripts are submitted to journals, we then work one-onone with trainees on their initial grant applications.

The central and most critical component of this training model defines the Center's overall objectives, the faculty it engages, the types of training that it provides to students and faculty, the choice of journals to which participants will submit manuscripts, the character of the publications themselves, the types of grant applications that faculty will submit, and, ultimately, the impact and reputation of the Center, which is to say how it defines itself and its contributions in the context of world science. In our case, the choice in light of the faculty initiative seemed preordained. Faculties composed of individuals from different disciplines were seriously committed to adding a neuroimaging approach to their research investigations. They had already submitted proposals for funding to support such a plan. They had asked and worked with Administration to pursue this goal. At the same time, they were not interested in abandoning their mainstream areas of expertise to become neuroscientists. They had already established significant reputations in their major fields of study. Rather, they want- ed to remain expert in their disciplines while addressing broader questions that they believed the addition of a neuroscience perspective and methods would aid them in addressing. These faculties were already engaged in mentoring students and teaching courses in their disciplines while making serious efforts to broaden their own approaches to the sciences. The training model, as a consequence, had to provide them with the skills and knowledge to integrate the neuroscience literature and methods in combination with their existing research methods to address those interests. They were willing to invest their most precious commodity, their time, in taking the chance that adding these new approaches would enable them to make significant and even major breakthroughs that would take their fields of study to new levels of understanding. While most neuroimaging centers engage outstanding neuroscientists who utilize various imaging tools to address a range of neuroscience and behavior questions, our Center planned to take experts in a much wider range of behavior research than is currently addressed by such centers. It would then provide them with the tools and training that in combination with their broad behavioral science expertise would lead to breakthrough science in domains never addressed.

Current Progress and Plans for the Future. In the 10 months since the Director was hired to help organize, focus and train interested faculty and students, much has happened. Across five twoday workshops (Step 1 of our seven step training program), 134 faculty and students were in attendance. Presentations on the Center's resources, training and 
goals were presented to 26 departments across all colleges of the University. In addition, presentations were made to a number of state, medical school and hospital groups regarding Center goals and initiatives. Collaborations have now been established with two hospitals in Lincoln and one in Omaha as well as with the Medical Center in Omaha. Three faculty have already been sponsored for NIH K award submissions and six students have submitted NSF predoctoral training applications and $\mathrm{NIH}$ NRSA training applications. A competitive State of Nebraska Research Initiative grant for \$1.2 million was awarded that augmented funds for purchasing imaging and computing equipment for the Center. In the meantime, plans are finalized for installing the 3T fMRI in temporary housing so that research using the magnet can hopefully begin in January. The building, with plans finalized for housing the Center, is now under construction with a completion date in early 2013. In the meantime, five high-density event-related potential /EEG systems are being used by faculty from three different departments to address research questions that are unique to their particular fields of interest. Another 30+ faculty and students are continuing their training through the 7-steps outlined earlier. This fall and winter will be a critical time for the Center. The hope is that spring will see manuscripts being submitted from faculty and students citing a literature and using neuroimaging techniques that were unknown to them a year ago. Especially noteworthy and critical to our goals is that these manuscripts will break new and fertile ground in their own areas of expertise that have never been addressed before in the neuroscience literature. The success of the faculty, students and Center are intertwined. The excitement is palatable. While the future is never certain, all the tools needed for success are here. The most important of these of course is the talent, enthusiasm and energy possessed by the faculty and students to conduct cutting-edge science! 